\title{
Inserção dos jovens no mercado de trabalho
}

\author{
ANSELMO LUIS DOS SANTOS ${ }^{I}$ \\ e DENIS MARACCI GIMENEZ II
}

\section{Introdução}

$\mathrm{O}$ OBJETIVO deste trabalho é analisar o padrão de inserção do jovem no mercado de trabalho brasileiro entre 2004 e 2015. Nos quadros da retomada do crescimento econômico, das melhorias sociais, dos avanços no mercado de trabalho brasileiro, e mais recentemente da desaceleração da economia e do ritmo de geração de empregos, observam-se importantes transformações e melhorias também nas condições de inserção dos jovens no mercado de trabalho.

Tal análise se justifica, por um lado, pelo dinamismo recente do mercado de trabalho brasileiro que facilitou a inserção do jovem e a obtenção do "primeiro emprego", por outro, por ser um segmento da força de trabalho com grande vulnerabilidade social, historicamente com elevada taxa de participação em um mercado de trabalho estruturalmente heterogêneo. A elevada taxa de participação dos jovens no mercado de trabalho, em comparação com outros países, sempre esteve associada no Brasil a formas degradantes de exploração da atividade laboral, com evidentes impactos negativos sobre as condições de educação dos jovens.

Nesse sentido, retratar o dinamismo recente do mercado de trabalho brasileiro e seus impactos sobre o segmento jovem da força de trabalho não parece suficiente para essa análise. Com efeito, as mudanças demográficas recentes, assim como o impacto das políticas de proteção social e as voltadas para o mercado de trabalho, estão exercendo importante papel sobre a forma e as condições pelas quais os jovens brasileiros estão se inserindo no mercado de trabalho nacional. Ante o dinamismo do mercado de trabalho, as mudanças demográficas, na proteção social e trabalhista, observam-se, em tese, melhores condições tanto para a inserção laboral do jovem brasileiro quanto para a redução das elevadas taxas de atividade desse segmento.

A análise partirá da caracterização do padrão histórico de inserção dos jovens no mercado de trabalho brasileiro no período de industrialização e, depois, nas décadas de relativa estagnação econômica entre 1981 e 2003. Em seguida, diante das severas transformações demográficas das últimas décadas, cujos impactos são inequívocos sobre a constituição da força de trabalho juvenil, e ante as condições de retomada do crescimento da economia brasileira a partir de 
2004 e seus reflexos sobre o mercado de trabalho, serão abordadas as mudanças no processo de inserção do jovem no mercado de trabalho brasileiro na última década.

Por fim, antes das considerações finais, como um importante aspecto do processo de melhoria das condições sociais dos jovens no Brasil na última década, tratar-se-á do avanço das políticas sociais e daquelas voltadas para o mercado de trabalho. O programa Bolsa Família, a política de valorização do salário mínimo, a estruturação do Programa Universidade para Todos (Prouni), assim como o financiamento estudantil (Fies) e a ampliação das vagas nas escolas técnicas e federais de nível superior, entre outros, estabeleceram melhores condições para a inserção laboral ou ainda, para a redução da elevada atividade do jovem brasileiro no período 2004-2015.

\section{Desenvolvimento e o padrão histórico de inserção do jovem no mercado de trabalho brasileiro}

A análise do processo de inserção do jovem no mercado de trabalho brasileiro não pode ser dissociada das características concentradoras e excludentes do processo de desenvolvimento socioeconômico brasileiro, responsável pela construção de uma das nações com os mais elevados índices de desigualdade econômica, regional e entre diversos segmentos da sociedade. Aos negros e seus descendentes - e também aos mestiços - o significado da "libertação" foi a da liberdade para escolherem algumas das formas possíveis para continuarem marginalizados e excluídos dos benefícios promovidos pela economia cafeeira e pelo lento processo de diversificação da estrutura produtiva e social (Fernandes, 2008).

O Brasil da República Velha era um país com uma população muito jovem. Os dados do Censo de 1920 indicam que entre uma população total de 30,6 milhões de habitantes, 21,9 milhões de pessoas $(71,5 \%)$ tinham até 29 anos, mais de 13 milhões $(41,1 \%)$ tinham até 14 anos, e 6,4 milhões $(20,9 \%)$ tinham até 6 anos de idade (IBGE, 1939).

Não somente o Brasil da República Velha é um país de jovens, mas também é um país pobre, com uma renda per capita baixa e fortemente concentrada. Em 1920, logo após o desfecho da Primeira Guerra Mundial, estima-se que a renda per capita brasileira (US\$ 963) representava $17,3 \%$ da norte-americana, $27,7 \%$ da argentina, $29,0 \%$ do Ocidente europeu e pouco mais de $58 \%$ da renda per capita média da América Latina (Maddison, 2001).

Nessas condições, com a pobreza das famílias e as dificuldades de acesso a um sistema educacional extremamente reduzido e limitado às elites e às classes médias abastadas, a imensa maioria da grande população infantojuvenil seria empurrada para o trabalho: nas atividades de subsistência no meio rural e urbano; como ajudantes do trabalho familiar; como trabalhadores por conta própria em atividade extremamente precárias no meio urbano; como assalariados nas ocupações associadas ao trabalho manual, às extensas jornadas, aos reduzi- 
dos rendimentos, a elevados índices de acidentes de trabalho, especialmente na construção, na indústria têxtil, nas atividades agrícolas e extrativas, no comércio informal.

O período de industrialização do Brasil (1930-1980) produziu uma brutal transformação das estruturas econômicas e sociais. O crescimento econômico acelerado em todo o período, particularmente no pós-guerra, com uma taxa média anual de crescimento do produto de 7,3\% (1947-1980) foi determinante para que a renda per capita brasileira aumentasse mais de sete vezes entre $1920 \mathrm{e}$ 1980, chegando a US\$ 7.098 no início da década de $1980,{ }^{1}$ mesmo com a forte expansão da população, que ampliou-se quatro vezes no período (30 milhões para 120 milhões de habitantes). ${ }^{2}$

O crescimento econômico acelerado e o avanço da industrialização produziu uma migração rural urbana das mais intensas do século XX. Entre 1950 e 1980, quase 40 milhões de brasileiros deixaram o campo e migraram para as áreas urbanas em busca das oportunidades geradas pela industrialização, fortemente concentradas na região Sudeste do país, particularmente na Região Metropolitana de São Paulo.

Nos quadros da rápida urbanização do Brasil e das oportunidades de emprego nos grandes centros urbanos, observa-se uma intensa mobilidade social ascendente, a formação de uma "nova classe média" e a queda acentuada da pobreza. Não obstante, a rápida expansão da capacidade de produção de riqueza material que transformou a estrutura social e promoveu forte mobilidade ascendente foi incapaz de eliminar a pobreza no país e diminuir a desigualdade, colocando o Brasil em 1980 entre aqueles países de maior desigualdade do mundo (Henrique, 1999, p.103).

As elevadas taxas de crescimento até o final dos anos 1970 permitiram a incorporação de milhares de brasileiros aos setores organizados da sociedade, produzindo uma mobilidade social ascendente, cuja peça fundamental era um mercado de trabalho extremamente dinâmico.

Conforme a interpretação de João Manuel Cardoso de Mello e Fernando Novais (2009), a constituição desse modelo extremamente dinâmico e concentrador fora determinada pela ordem política instaurada no país a partir do golpe militar de 1964 que "produziu, ao longo de seus vinte e um anos de vigência, uma sociedade deformada e plutocrática". Viu-se, assim, a permanência de constrangedores níveis de desigualdade, pobreza, analfabetismo, mortalidade infantil, entre outras mazelas, em meio a um acelerado crescimento econômico, processo que Maria da Conceição Tavares e José Carlos de Assis (1985) denominam como uma "modernização conservadora" do regime autoritário entre 1964-1985.

Em meio a tal modelo de desenvolvimento econômico e social, além de uma elevada participação dos jovens no total da população $(33,5 \%$ para a faixa de 10 a 24 anos), em 1980 a taxa de participação dos jovens de 10 a 24 anos no 
mercado de trabalho brasileiro era de mais de $40 \%$ (55,3\% entre 15 a 24 anos), quando o Brasil já alcançava um estágio mais avançado, com uma sociedade urbana e industrial e com a oitava economia do mundo em $1980 .{ }^{3}$ Assim, no início da década de 1980, a taxa de participação dos jovens brasileiros no mercado de trabalho era uma das mais elevadas da América Latina, maior em comparação a muitos países com mesmo grau de desenvolvimento e incomparavelmente superior aos países desenvolvidos.

A parcela dos jovens egressos das famílias mais bem situadas na estrutura social, especialmente das regiões mais desenvolvidas do Sudeste, foi extremamente beneficiada pelas novas oportunidades de escolarização formal, inclusive no ensino médio e no superior, assim como pela facilidade de ingresso em boas condições num mercado de trabalho extremamente dinâmico. Com efeito, para a imensa maioria pobre da sociedade - negros, mulatos, mestiços, e também brancos migrantes ou residentes nas regiões mais pobres -, a estratégia de melhoria de vida ou de ascensão social passou pela manutenção das crianças e jovens no mercado de trabalho, que iniciavam o trabalho até mesmo com menos de dez anos de idade. Em outras palavras, num contexto de extrema e adversa concorrência num mercado de trabalho marcado por elevado excedente de força de trabalho, baixos salários e enorme desigualdade, tratava-se de uma estratégia de elevar a renda familiar por meio do aumento de familiares ocupados.

As décadas de 1980 e de 1990 no Brasil foram marcadas por crises externas, elevada inflação, ajuste recessivo e exportador, reformas e políticas econômicas neoliberais, reduzido crescimento econômico, que contribuíram para deteriorar o mercado de trabalho nos anos 1980 e provocar uma profunda desestruturação do mercado e das relações de trabalho no Brasil nos anos 1990. Embora a taxa de crescimento populacional já tivesse infletido no final dos anos 1960, o ritmo de crescimento da população jovem economicamente ativa ainda era elevado e maior do que o ritmo de crescimento da população em idade ativa, de forma que a taxa de participação dos jovens de 15-24 anos subiu de 55,3\% em 1980, para 56,5\% em 1991 e atingiu 61,1\% em 2000, seu patamar máximo na história urbana e industrial brasileira (Tabela 1 ).

Nos anos 1980 e 1990, portanto, num contexto de crise econômica, transformações estruturais adversas ao emprego e aos trabalhadores, assim como de elevação da taxa de participação juvenil, os impactos sobre a inserção dos jovens brasileiros no mercado de trabalho foram imensamente adversos. Com efeito, em 2003, ano das mais elevadas taxas de desemprego no Brasil, a taxa de desemprego metropolitana na faixa etária de 15 a 24 anos alcançou $25,3 \%$, sendo ainda muito maior na faixa de 15 a 17 anos $(38,1 \%)$, do que os $23,4 \%$ da faixa de 18 a 24 anos (IBGE 2012). 
Tabela 1 - Evolução da população total e da população jovem. Brasil, 1991 - 2010

\begin{tabular}{|c|c|c|c|}
\hline População (em mil) & 1991 & 2000 & 2010 \\
\hline Total (A) & $146.825,5$ & $169.799,2$ & $190.755,8$ \\
\hline Na faixa de 15-24 anos (B) & $28.582,4$ & $34.081,3$ & $34.227,6$ \\
\hline Economicamente Ativa de 15-24 anos (C) & $16.151,2$ & $20.812,2$ & $19.208,5$ \\
\hline (em \%) & $19,5 \%$ & $20,1 \%$ & $17,9 \%$ \\
\hline$(\mathrm{C}) /(\mathrm{A}) \quad(\mathrm{em} \%)$ & $11,0 \%$ & $12,3 \%$ & $10,1 \%$ \\
\hline Taxa de Participação (C) / (B) (em \%) & $56,5 \%$ & $61,1 \%$ & $56,1 \%$ \\
\hline
\end{tabular}

Fonte: IBGE, Censos Demográficos.

Apesar do processo de transição demográfica iniciado no final da década de 1960, com uma expressiva redução da taxa de natalidade e do ritmo de crescimento da população brasileira, no período 1980-2000, o ritmo de crescimento da população ainda era muito elevado, com impactos sobre o elevado ritmo de crescimento da população ativa, demandando mais ocupações num cenário adverso. Nesse contexto, somente ao final da primeira década dos anos 2000 a trajetória de transição demográfica brasileira resultou numa redução expressiva da taxa de participação dos jovens de 15 a 24 anos (para 56,1\%) e na redução absoluta da população jovem ( 15 a 24 anos) total, em idade ativa e economicamente ativa. Simultaneamente, tal redução foi acompanhada do expressivo aumento da expectativa de vida dos brasileiros e da elevação da participação das pessoas com 60 anos ou mais na população total e na estrutura ocupacional.

De fato, somente a partir de 2004, num contexto marcado por taxas mais elevadas de crescimento econômico, por impactos favoráveis do processo de transição demográfica sobre a demanda juvenil por trabalho e por um conjunto importante de políticas sociais e voltadas para o trabalho, não somente o desemprego caiu, como vários aspectos relativos à inserção do jovem no mercado de trabalho e a diversos aspectos sociais melhoraram de forma significativa, como veremos nas próximas seções.

\section{Mudanças no processo de inserção do jovem no mercado de trabalho brasileiro no período 2004-2015}

No período 2004-2010, a economia brasileira apresentou uma taxa média de crescimento do PIB de cerca de $4 \%$, com fortes impactos positivos sobre a geração de ocupações, o crescimento do emprego formal, a elevação dos salários (especialmente os mais baixos), a redução da participação da ocupação informal na estrutura ocupacional e uma forte redução do desemprego (Baltar et al., 2010; Santos, 2011). Os dados do conjunto das regiões metropolitanas investigadas mensalmente pelo IBGE mostram uma tendência semelhante, mesmo quando se considera o período 2003-2013. No entanto, esses dados mais atualizados (2014-2015) apontam para uma queda da população ocupada nas 
metrópoles, estagnação do processo de ampliação da formalização e forte elevação do desemprego.

Tabela 2 - Evolução dos indicadores selecionados do mercado de trabalho. Brasil e Regiões Metropolitanas, 2000 a 2013. Variação no período em \%

\begin{tabular}{l|c|c|c|c}
\hline População de 10 anos ou mais & Ocupada & $\begin{array}{c}\text { Com } \\
\text { emprego } \\
\text { Formal }^{*}\end{array}$ & $\begin{array}{c}\text { Com } \\
\text { ocupação } \\
\text { Informal }\end{array}$ & $\begin{array}{c}\text { Desem- } \\
\text { pregada }\end{array}$ \\
\hline Brasil (Censos) 2000-2010 & 31,6 & 58,4 & $13,3 \%$ & $-60,4$ \\
\hline Regiões Metropolitanas (PME) - 2003-2011 & 21,3 & $40,7^{\star}$ & $-9,3^{\star \star}$ & $-45,3$ \\
\hline Regiões Metropolitanas (PME) - 2003-2013 & 25,0 & $51,6^{*}$ & $-17,3^{\star *}$ & $-49,5$ \\
\hline $\begin{array}{l}\text { Regiões Metropolitanas (PME) - 2014-2015. } \\
\text { (média de jan. a jul.) }\end{array}$ & $-0,8$ & 0,01 & $-3,5^{\star *}$ & 16,6 \\
\hline
\end{tabular}

Fonte: IBGE; Censos, PNAD, PME.

*Contribuintes à previdência social

**Não contribuintes à previdência social.

No conjunto do país, observa-se que no período 2000-2010, a população economicamente ativa cresceu num ritmo maior $(+20,7 \%)$ em comparação à população total $(+12,3 \%)$ e à população em idade ativa $(+18,3 \%)$. Mas esses ritmos de crescimento foram bem menores do que nas décadas anteriores e resultaram numa expansão muito pequena da taxa de participação $(+2,0 \%)$, considerando que o patamar dessa taxa era relativamente baixo em 2000, num contexto de desemprego elevado. Portanto, a evolução demográfica contribuiu para que fossem maiores e mais positivos os impactos do crescimento econômico médio de $4 \%$ - ritmo bem menor do que o verificado no auge do processo de industrialização, de 7\% entre 1950-1980 - sobre o mercado de trabalho. Os dados recentes disponíveis para as regiões metropolitanas sobre evolução da população em idade ativa, da população economicamente ativa e da taxa de participação mostram que a reversão dos impactos positivos não se deveu a um forte aumento da demanda por trabalho, indicando que a recente precarização do mercado de trabalho ocorre apesar dos impactos positivos da transição demográfica (Tabela 3 ). 
Tabela 3 - Evolução dos indicadores selecionados do mercado de trabalho. Brasil e regiões metropolitanas, 2000-2013. Variação no período em \%

\begin{tabular}{l|c|c|c}
\hline População com 10 anos ou mais & $\begin{array}{c}\mathrm{PIA}^{*} \\
(\mathrm{~A})\end{array}$ & $\begin{array}{c}\mathrm{PEA}^{*} \\
(\mathrm{~B})\end{array}$ & $\begin{array}{c}\text { Taxa de } \\
\text { Participação* } \\
(\mathrm{B}) /(\mathrm{A})\end{array}$ \\
\hline Brasil (Censos) 2000-2010 & 18,3 & 20,7 & 2,0 \\
\hline Regiões Metropolitanas (PME) - 2003-2013 & 15,7 & 15,6 & $-0,04$ \\
\hline Regiões Metropolitanas (PME) - 2014-2015 & 0,98 & 0,75 & $-0,02$ \\
\hline
\end{tabular}

Fonte: IBGE; Censos, PNAD, PME.

* 10 anos ou mais.

Essa transição demográfica, num contexto de mais elevado crescimento econômico, não somente significou a redução do peso dos jovens na estrutura ocupacional, como a redução de sua taxa de atividade e de participação no mercado de trabalho brasileiro. E, nesse movimento, apresentou não somente impactos positivos para o mercado de trabalho em geral, mas também para o mercado de trabalho dos próprios jovens, cujo montante de desocupados reduziu-se em quase 55\% até 2013, mesmo quando o número de jovens ocupados vinha caindo. Entretanto, com a recente tendência de estagnação/recessão observada no período 2014-2015, a redução do peso dos jovens e de sua taxa de atividade não foi capaz de evitar uma forte elevação do número de desocupados, maior do que para o conjunto dos ocupados (Tabela 4).

Tabela 4 - Evolução dos indicadores do mercado de trabalho dos jovens de 10 a 24 anos. Brasil e regiões metropolitanas. Vários períodos. Variação no período em $\%$

\begin{tabular}{l|c|c|c|c|c}
\hline & PIA & PEA & $\begin{array}{c}\text { Taxa } \\
\text { de } \\
\text { Part. }\end{array}$ & Ocupação & Desocupação \\
\hline $\begin{array}{l}\text { Regiões Metropolitanas } \\
\text { PME - 2003-2013 }\end{array}$ & $-10,5$ & $-17,8$ & $-8,2$ & $-5,4$ & $-54,5$ \\
\hline $\begin{array}{l}\text { Regiões Metropolitanas } \\
\text { PME - 2010-2013 }\end{array}$ & $-7,9$ & $-7,1$ & $-3,8$ & $-4,9$ & $-18,7$ \\
\hline $\begin{array}{c}\text { Regiões Metropolitanas } \\
\text { PME - 2014-2015 (jan a jul ) }\end{array}$ & $-3,6$ & $-3,1$ & 0,48 & $-7,0$ & 20,6 \\
\hline
\end{tabular}

Fonte: IBGE: Banco Sidra: Censos, PNAD e PME. Elaboração própria.

Tudo isso sugere que o segmento juvenil, que apresenta uma das mais elevadas taxas de desemprego, deve ser um dos segmentos mais afetados pela continuidade da atual crise econômica. Não somente pela reversão das tendências de melhoria da situação financeira das famílias pobres e miseráveis (Quadros et al., 
2013), do forte aumento do emprego formal, de expressiva elevação do salário mínimo e dos salários definidos em negociações coletivas, das políticas de transferência de renda, das melhorias nos rendimentos dos trabalhadores por conta própria, mas também em razão dos impactos negativos da recente tendência de estagnação/recessão sobre o financiamento das políticas sociais e voltadas para o trabalho, que tiveram fortes impactos sobre as condições de uma parcela dos jovens que foi capaz de se manter na escola e de reverter a anterior tendência de forte expansão do trabalho infantojuvenil, juntamente com seu amplo e perverso significado social e para o mercado de trabalho brasileiro, aspectos que serão discutidos na seção seguinte.

\section{Políticas públicas e a inserção do jovem no mercado de trabalho}

As transformações das políticas públicas no Brasil na última década, em especial da política social brasileira, foram decisivas para a redução da elevada taxa de atividade do jovem no mercado de trabalho brasileiro. Também tiveram efeitos positivos sobre as condições de inserção laboral juvenil no dinâmico mercado de trabalho brasileiro entre 2004 e 2015.

A evolução do sistema educacional brasileiro na última década é um ponto central no tratamento da questão da inserção do jovem no mercado de trabalho brasileiro na última década. De acordo com o Censo da Educação Básica do Inep/MEC, observa-se forte expansão de vagas nos anos 2000. Em 2012, o Brasil contava com 50,5 milhões de alunos matriculados na educação básica (ensino fundamental e médio). Desses alunos, 40,9 milhões estavam no ensino fundamental e 9,6 milhões, no ensino médio (8,3 milhões no ensino médio "tradicional" e pouco mais de 1,3 milhão no "ensino médio técnico"). Dados do MEC indicam ainda que 1,8 milhão de estudantes concluem o ensino médio a cada ano no Brasil e que o país conta com um estoque de 7,6 milhões de jovens de 18-24 anos que já concluíram o ensino médio e não ingressaram no ensino superior.

Com efeito, o mais significativo fenômeno relativo ao sistema educacional brasileiro, com impacto sobre os jovens, foi a expansão do ensino superior ao longo da última década. Entre 2002 e 2012 o número de alunos no ensino superior dobrou no Brasil, passando de 3,5 milhões para mais de 7 milhões de alunos. Desse universo de matriculados em 2012, 5,9 milhões estavam em cursos presenciais e mais de 1 milhão de estudantes, em cursos a distância. Os ingressantes saltaram de 1,4 milhão para 2,7 milhões e os concluintes, de 479 mil para mais de 1 milhão de estudantes. ${ }^{4}$ A expansão do ensino médio e superior no Brasil nos anos 2000 ampliou o universo de matriculados para mais de 16,6 milhões de alunos nesses níveis de ensino. Tomando como referência a população total brasileira, em 2012, com idade entre 18 e 24 anos - 22,5 milhões de pessoas -, percebe-se que o número de matriculados no ensino médio e superior representava $73,3 \%$ da população desse grupo etário. 
Em 2012 eram 31.866 cursos de graduação no Brasil, em 2.416 instituições de ensino superior (304 públicas e 2.112 privadas). Do total de alunos em 2012 , 5,1 milhões (73\%) estavam em instituições privadas e 1,8 milhão (27\%), em instituições públicas. No mesmo ano, do total de candidatos inscritos em vestibulares, $56,3 \%$ almejavam as universidades públicas (6,7 milhões) e apenas 547.897 ingressaram nessas instituições (cf. MEC/Inep). Diante desses dados, conclui-se que, a despeito da expansão de vagas nas instituições públicas e das diferenças entre escolas públicas e privadas relativas à qualidade do ensino, foram as vagas criadas nas instituições privadas que ampliaram sobremaneira as possibilidades de inserção dos jovens brasileiros no ensino superior nos anos 2000.

Dois grandes programas do governo federal foram importantes para tal expansão das vagas no ensino superior privado no Brasil: o Programa Universidade para Todos (Prouni) e o Financiamento Estudantil (Fies). Criado pelo governo federal em 2004 e institucionalizado pela Lei n.11.096, em 13 de janeiro de 2005, por meio do Ministério da Educação, o Programa Universidade para Todos (Prouni) concede bolsas de estudo integrais e parciais $(50 \%) \mathrm{em}$ instituições privadas de ensino superior, em cursos de graduação e sequenciais de formação específica, a estudantes brasileiros, sem diploma de nível superior. As instituições privadas de ensino que aderem ao programa recebem, em contrapartida, isenção de tributos.

Dirigido aos estudantes egressos do ensino médio da rede pública ou da rede particular na condição de bolsistas integrais, com renda familiar per capita máxima de três salários mínimos, o Prouni abriu as portas do ensino superior brasileiro para milhares de jovens estudantes de baixa renda e foi decisivo para a forte expansão do ensino superior no Brasil nos anos 2000. Segundo dados do Ministério da Educação, entre 2005 e 2013, 1.920 .332 de bolsas foram ofertadas e mais de 1 milhão de alunos foram atendidos. Acrescente-se que entre 2009 e 2013, mais de 250 mil bolsas foram oferecidas por ano em média. Para se dimensionar a importância do Prouni, em 2013, o programa contava com um estoque de mais de 1.200 milhão de bolsas vigentes, representando em torno de $17 \%$ do total de matriculados no ensino superior, e $23 \%$ das matrículas no ensino superior privado.

Articulado ao Prouni, ${ }^{5}$ o Fundo de Financiamento Estudantil (Fies) é um programa do Ministério da Educação que financia cursos de graduação para estudantes matriculados em instituições não gratuitas. Podem recorrer ao financiamento os estudantes matriculados em cursos superiores que tenham avaliação positiva nos processos conduzidos pelo Ministério da Educação. A procura pelo Fies ampliou-se sobremaneira no início da segunda década do século XXI. Em 2010, foram firmados 75,9 mil contratos; em 2011, foram 153,5 mil; 2012, outros 377,6 mil; e em 2013, mais 556,5 mil contratos. Estima-se, assim, que ao final de $2013,17 \%$ do total de estudantes nas instituições particulares de ensino superior tinham contrato com o Fies e que os recursos provenientes do fundo representariam cerca de $25 \%$ da receita das instituições privadas de ensino superior no país. 
Importante destacar que, a despeito da forte expansão do ensino superior no Brasil, parte importante dos jovens que concluem o ensino médio não terá acesso imediato ao ensino superior. Basta considerar, nesses termos, o fluxo anual de quase 2 milhões de concluintes do ensino médio e o estoque de quase $8 \mathrm{mi}$ lhões de brasileiros que já concluíram o ensino médio e ainda não ingressaram na universidade.

Nas condições atuais do mercado de trabalho brasileiro, a demanda por profissionais com formação técnica indica que a expansão do ensino médio profissionalizante é uma importante alternativa para a política pública no Brasil. Segundo dados do Ministério da Educação, em 2013, pouco mais de 10\% das vagas no ensino médio brasileiro eram vagas no ensino técnico-profissionalizante. Com o objetivo de ampliar a oferta de cursos de educação profissional e tecnológica, o governo federal criou em 2011 o Programa Nacional de Acesso ao Ensino Técnico e Emprego (Pronatec) que oferece cursos gratuitos nas escolas públicas federais, estaduais e municipais, nas unidades de ensino Senai, Senac, Senar, Senat, e também em instituições privadas de ensino superior e de educação profissional técnica de nível médio. A partir de sua criação, o programa atingiu 8 milhões de matrículas em dezembro de 2014, sendo 2,3 milhões em Cursos Técnicos e quase 6 milhões em cursos de Formação Inicial e Continuada.

Apesar desse robusto movimento de ampliação de vagas no sistema de ensino brasileiro, ainda é muito significativo o número de jovens fora da escola no Brasil. Dados da Pesquisa Nacional por Amostra de Domicílios (PNAD-IBGE) de 2012 indicam que o Brasil contava com 18 milhões de jovens entre 15 e 24 anos fora da escola, e 1,8 milhão não cursaram o ensino médio. Entre aqueles com idade entre 18 e 24 anos, mais de 14,6 milhões não estudavam, ou seja, $64,8 \%$ do total dessa faixa etária.

Ademais, nota-se que além das dificuldades ainda presentes quanto ao acesso ao sistema educacional, permanecem, para muitos jovens, as dificuldades de inserção laboral, apesar do dinamismo do mercado de trabalho brasileiro nos anos 2000. Quando segmentados pelas atividades exercidas, a maior parcela dos jovens brasileiros entre 15 e 29 anos somente trabalhava em 2012 (45,2\%), $21,6 \%$ somente estudavam e 13,6\% trabalhavam e estudavam. Chama a atenção, nesse caso, que um em cada cinco jovens brasileiros com idade entre 15 e 29 anos não estudava e não trabalhava em 2012. Esse número de jovens que não trabalhavam e não estudavam é mais elevado entre aqueles com idade entre 18 e 24 anos. Nessa faixa etária, 14,5\% somente estudavam, 14,8\% trabalhavam e estudavam, $47,3 \%$ deles somente trabalhavam e $23,4 \%$ não trabalhavam e não estudavam. Neste último caso, eram 5,2 milhões de jovens em 2012, a maior parte mulheres $(70,3 \%)$ onde $58,4 \%$ já tinham pelo menos um filho. ${ }^{6}$

Mesmo considerando essas indicações de dificuldades dos jovens brasileiros para estudar e trabalhar, são inequívocas as melhorias das condições de inserção laboral e de acesso ao sistema de ensino na última década. Com efeito, 
o avanço de um conjunto de políticas públicas nos anos 2000 cumpriu papel fundamental na ampliação da proteção social dos indivíduos e famílias e, portanto, melhorando as condições de inserção do jovem no mercado de trabalho.

Uma área da política pública com forte impacto na proteção das famílias e dos indivíduos é a habitação. Historicamente, a questão habitacional, compreendida no complexo quadro da organização do espaço urbano, caracterizou-se como um dos problemas mais graves no que se refere à questão social e à proteção das famílias e indivíduos no Brasil.

O governo brasileiro lançou em março de 2009 o Programa Minha Casa, Minha Vida (MCMV), a maior iniciativa na área habitacional desde o colapso da política implementada nos anos do regime militar (1964-1985). De forma geral, o MCMV parte do detalhado diagnóstico do Plano Nacional de Habitação elaborado pelo governo em 2004, onde está indicado que $90,9 \%$ do déficit habitacional de 7,2 milhões de moradias, segundo os dados do Censo Demográfico (IBGE de 2000), concentravam-se em famílias com renda de até três salários mínimos. Em 2007, o déficit habitacional no Brasil foi estimado em 5,5 milhões de moradias, caindo em 2012 para 5,2 milhões, num quadro de acelerada expansão do número de domicílios no período, que saltou de 55,9 milhões para 62,9 milhões. Ressalte-se que 74\% do déficit habitacional em 2012 eram compostos por famílias com renda de até três salários mínimos.

Entre 2009 e 2013, no âmbito do Programa Minha Casa, Minha Vida (MCMV), foram entregues, segundo a Caixa Econômica Federal, mais de 1,4 milhão de unidades habitacionais, que beneficiaram cerca de 7 milhões de pessoas de famílias de baixa renda.

Na verdade, os dados indicam que 50\% das unidades do MCMV foram destinadas a famílias mais pobres e com muitos jovens, com renda de até R $\$ 1.600$; 459 mil (28\%) para famílias com renda entre R\$ 1.600 e R\$3.100; e 353 mil moradias (22\%) foram destinadas a famílias com renda de até R\$5.000. Assim, com importante colaboração do MCMV, estudo recente do Instituto de Pesquisa Econômica Aplicada (Ipea) indica que "entre os anos de 2007 e 2012, houve redução sistemática do indicador do déficit habitacional, que passou de 5,5 milhões de domicílios em 2007 para 5,2 milhões de domicílios em 2012", num cenário de forte expansão do número de domićlios (Neto et al., 2013, p.4).

Outro campo de expansão da proteção aos indivíduos e famílias que favoreceu a melhor condição de inserção do jovem no mercado de trabalho brasileiro foi a previdência social. Num cenário de aquecimento do mercado de trabalho e de expansão da formalização das relações de trabalho, ocorreu uma queda acentuada do percentual de "desprotegidos" da previdência social entre 2003 e $2011 .^{7}$

Esse universo de "desprotegidos" englobava, em 2003, mais de 27,1 milhões de ocupados ou $37,5 \%$ do total de ocupados. Esse número caiu para 24,7 milhões em 2011 ou $29,4 \%$ do total de ocupados. Evidentemente, a maior pro- 
teção previdenciária, mesmo com presença ainda de um enorme universo de "desprotegidos" é fonte de proteção e incremento à renda das famílias brasileiras, particularmente num período de forte valorização real do salário mínimo, piso dos benefícios previdenciários. Com efeito, na base da estrutura social e dos rendimentos, tal movimento fora reforçado pelo Programa Bolsa Família (PBF).

Lançado em 2003, o PBF é um programa de transferência direta de renda, com condicionalidades, para famílias em situação de pobreza (com renda mensal per capita entre $\mathrm{R} \$ 77,01$ e $\mathrm{R} \$ 154$ ) e extrema pobreza (com renda mensal per capita de até $\mathrm{R} \$ 77,00)$, associando a transferência do benefício financeiro do acesso aos direitos sociais básicos - saúde, alimentação, educação e assistência social. Entre 2003 e 2012, o número de beneficiários do Programa Bolsa Família saltou de 3,6 milhões de famílias para quase 14 milhões em 2012. Com um valor médio mensal dos benefícios em 2012 de R\$ 145,00, os desembolsos nesse ano foram da ordem de R 20 bilhões. ${ }^{8}$

Segundo o "Relatório de Avaliação do Programa Bolsa Família", elaborado em 2012 pelo Instituto Internacional de Pesquisa sobre Políticas Alimentares e pela empresa Datamétrica, para o Programa das Nações Unidas para o Desenvolvimento (PNUD) e para o Ministério do Desenvolvimento Social (MDS), o PBF teve forte influência na redução do trabalho infantil no Brasil, ajudou a diminuir o número de horas dedicadas ao trabalho doméstico entre crianças e adolescentes de 5 a 17 anos, com um decréscimo de 4,5 horas no geral e de 5 horas para os meninos. Estima-se que o PBF também influenciou a postergação da entrada no mercado de trabalho de crianças e adolescentes do sexo masculino. ${ }^{9}$

Em conjunto, um comportamento demográfico mais favorável, um mercado de trabalho dinâmico e o avanço de políticas públicas em áreas importantes da proteção social conformaram um cenário favorável à inserção mais adequada dos jovens brasileiros na vida laboral.

Sem ainda superar problemas históricos, como a elevada taxa de participação dos jovens num mercado de trabalho estruturado com baixos salários, o enorme contingente de trabalhadores desprotegidos, a baixa qualidade do ensino em todos os níveis do sistema de educação, os graves problemas urbanos com impactos inequívocos sobre a questão habitacional e a segurança dos jovens, entre outros, a forte desaceleração da economia brasileira a partir de 2013, com efeitos evidentes sobre o ritmo de geração de empregos e sobre a arrecadação fiscal - portanto, sobre as condições de financiamento das políticas públicas coloca em questão todas as relações virtuosas aqui indicadas entre economia, mercado de trabalho e políticas públicas, que favoreceram os jovens brasileiros entre 2004 e 2012. 


\section{Considerações finais}

Procuramos demonstrar que nas condições do desenvolvimento capitalista no Brasil, tardio e periférico, a elevada taxa de participação dos jovens e sua precária inserção no desorganizado mercado de trabalho nacional é uma expressão do modelo excludente de organização do país. O bem-sucedido esforço de industrialização entre 1930 e 1980, que produziu uma complexa sociedade urbana industrial e a oitava economia do mundo, foi incapaz de alterar estruturalmente esse quadro, agravado pelos efeitos regressivos da relativa estagnação econômica que assolou o país entre a década de 1980 e o início dos anos 2000 .

No período de crescimento econômico entre 2004 e 2012, com evidentes efeitos positivos sobre o mercado de trabalho e sobre a estrutura social brasileira, ampliaram-se os espaços de inserção laboral dos jovens. Não somente os espaços foram ampliados, como a qualidade dos postos de trabalho oferecidos evoluiu positivamente, em razão da melhoria geral da estrutura de emprego e de renda.

Destacamos que as melhores condições de inserção laboral do jovem coexistiram com a diminuição da pressão pela entrada no mercado de trabalho brasileiro. A taxa de participação dos jovens caiu sobremaneira, determinada, simultaneamente, pela própria melhoria do emprego e da renda das famílias, pela menor pressão demográfica e pela ampliação de políticas públicas, particularmente na área social. Em síntese, os efeitos do crescimento econômico foram potencializados por um quadro demográfico favorável e pela estruturação de políticas públicas. Assim, materializou-se uma situação extremamente favorável aos jovens brasileiros, com mais e melhores empregos, e ademais, com queda da taxa de participação.

Todavia, o crescimento de $0,1 \%$ do produto em 2014 e as estimativas para 2015 da maior retração da economia brasileira desde a recessão do início da década de 1990 vêm conduzindo o país para uma rápida reversão desse quadro de relações virtuosas. Por um lado, a degradação do mercado de trabalho. Dados da Pesquisa Mensal de Emprego para julho de 2015 indicam que, no conjunto das regiões metropolitanas, a taxa de desocupação subiu de 4,9\% para 7,5\% em 12 meses. Também indicam que o rendimento médio real caiu $2,4 \%$ e a massa de rendimentos dos ocupados, 3,5\% no período (PME/IBGE). Por outro lado, os efeitos deletérios da estagnação econômica sobre a arrecadação pública e a desastrosa estratégia de "austeridade" adotada desde o início do ano têm provocado enormes constrangimentos em importantes políticas públicas. Como exemplo, o Ministério da Educação (MEC) anunciou que em 2015 a oferta de vagas no Pronatec cairá $60 \%$ e o número de novos contratos do Fies já caiu quase $50 \%$ no primeiro semestre do ano em comparação ao mesmo período de 2014.

A piora do emprego e da renda das famílias num cenário de estreitamento das políticas públicas e da proteção social tende a impulsionar de forma mais intensa a procura de emprego por parte dos jovens brasileiros. Esses, mais necessitados e menos protegidos, estarão diante de um mercado de trabalho em regressão. 
Notas

1 Dólares em paridade do poder de compra (PPP) em preços constantes de 2005.

2 Conforme comparações internacionais realizadas por Alan Heston, Robert Summers e Bettina Aten, Penn World Table Version 7.1, Center for International Comparisons of Production, Income and Prices at the University of Pennsylvania, July 2012.

3 Cf. IBGE, 2015. Disponível em: <http://seculoxx.ibge.gov.br/populacionais-sociais-politicas-e-culturais/busca-por-palavra-chave/trabalho/1030-populacao-economicamente-ativa $>$. Elaboração própria.

4 Segundo dados do MEC/Inep. Apesar do avanço no número de alunos, a evasão do sistema é elevadíssima: apenas 38\% dos ingressantes obtêm o diploma (237 mil no setor público e 812 mil no setor privado).

5 O bolsista parcial de 50\% do Prouni poderá utilizar o Fundo de Financiamento Estudantil (Fies) para custear os outros 50\% da mensalidade, sem a necessidade de apresentação de fiador na contratação do financiamento.

6 IBGE - Pesquisa Nacional por Amostra de Domicílios, 2012.

7 Anuário Estatístico da Previdência Social 2012. "Desprotegidos” são aqueles trabalhadores ocupados com idade entre 16 e 59 anos, que não são beneficiários e tampouco contribuem para algum regime de previdência.

8 Conforme publicado pelo Ministério do Desenvolvimento Social (MDS).

9 PNUD/MDS/Instituto Internacional de Pesquisa sobre Políticas Alimentares. Relatório de avaliação do Programa Bolsa Família. Brasília, julho de 2012. Segundo dados do Censo Escolar da Educação Básica do Ministério da Educação, em 2012, 14,8 milhões de jovens e crianças cumpriam a frequência escolar. A taxa de aprovação dos integrantes de famílias beneficiárias do programa foi superior à média nacional $(79,9 \%$ contra $75,2 \%)$ e a taxa de abandono significativamente inferior $(7,2 \%$ contra $10,8 \%)$.

\section{Referências}

BALTAR, P. E. A. et al. Moving towards Decent Work. Labour in the Lula government: reflections on recent brazilian experience. Global Labour University Working Papers, Berlim, n.9, may, 2010.

BARBOSA DE OLIVEIRA, C. A. Trabalho e desenvolvimento no Brasil. Carta Social $e$ do Trabalbo, Campinas, n.10, abril-junho 2010.

BARBOSA DE OLIVERIA, C. A.; HENRIQUE, W. Determinantes da pobreza no Brasil. Carta Social e do Trabalho, Campinas, n.11, julho-setembro 2010.

BARBOSA N.; SOUZA, J. A. P. de. A inflexão do governo Lula: política econômica, crescimento e distribuição de renda. In: SADER, E.; GARCIA, M. A. (Org.) Brasil: entre o passado e o futuro. São Paulo: Boitempo, 2010.

BELLUZZO, L. G. de M. Ensaios sobre o capitalismo no século XX. São Paulo; Campinas: Unesp; IE/Unicamp, 2004.

BRASIL - Ministério da Previdência Social. Anuário Estatístico da Previdência Social: Suplemento Histórico (1980 a 2011). Ministério da Previdência Social, Empresa de Tecnologia e Informações da Previdência Social. Brasília: MPS/Data, 2011. 
BRASIL - Ministério das Cidades. Política Nacional de Habitação. Brasília: Ministério das Cidades, 2004.

CARDOSO DE MELLO, J. M.; NOVAIS, F. Capitalismo tardio e sociabilidade moderna. Campinas: Edições Facamp; São Paulo: Editora Unesp, 2009.

CEPAL. A hora da igualdade - brechas por fechar, caminhos por abrir. Santiago do Chile: Cepal/ONU, 2010.

DIEESE. A situação do trabalho no Brasil na primeira década dos anos 2000. São Paulo: Dieese, 2012.

FERNANADES, F. A integração do negro na sociedade de classes. São Paulo: Editora Globo, 2008 (1 ${ }^{\text {a }}$ edição, 1964)

GIMENEZ, D. M. Ordem liberal e a questão social no Brasil. São Paulo: LTr, 2008.

HENRIQUE, W. O capitalismo selvagem: um estudo sobre desigualdade no Brasil. 1999. Tese (Doutorado) - Instituto de Economia, Universidade Estadual de Campinas. Campinas, 1999.

IBGE. Anuário estatístico do Brasil 1938. Rio de Janeiro: IBGE, v.4, 1939.

IBGE. Indicadores IBGE (2003-2011). Pesquisa Mensal de Emprego. Principais destaques da evolução do mercado de trabalho nas regiões metropolitanas abrangidas pela pesquisa. Rio de Janeiro: IBGE, 2012.

MADDISON, A. The world economy: a millennial perspective. Paris: OECD, 2001.

NETO, V. C. L; FURTADO, B. A.; KRAUSE, C. Estimativas do déficit habitacional brasileiro (PNAD 2007-2012). Nota Técnica do IPEA. Brasília, novembro de 2013.

QUADROS, W. Evolução recente da estrutura social brasileira. Texto para Discussão, Campinas, IE/Unicamp, n.148, nov. 2008.

QUADROS, W.; GIMENEZ, D. M.; ANTUNES, D. Afinal, somos um país de classe média? Mercado de trabalho, renda e transformações sociais no Brasil dos anos 2000. In: BARTELT, D. (Org.) A "nova classe média” no Brasil como conceito e projeto politico. Rio de Janeiro: Fundação Heinrich Böll, 2013.

SADER, E. (Org.) 10 anos de governos pós-neoliberais no Brasil: Lula e Dilma. São Paulo: Boitempo; Rio de Janeiro: Flacso Brasil 2013.

SANTOS, A. L. Trabalho no governo Lula: avanços e contradições. Revista ABET, São Paulo, v.X, n.2, jul.-dez. 2011.

TAVARES, M. da C.; ASSIS, J. C. de. Ogrande salto para o caos-a economia política e a política econômica do regime autoritário. Rio de Janeiro: Zahar, 1985.

RESUMO - O objetivo deste trabalho é analisar o padrão de inserção do jovem no mercado de trabalho brasileiro entre 2004 e 2015. A análise parte da caracterização do padrão histórico de inserção dos jovens no mercado de trabalho brasileiro e nas décadas de relativa estagnação econômica entre 1981 e 2003. Em seguida, considerando as trans- 
formações demográficas, a elevação do ritmo de crescimento econômico, as políticas sociais e voltadas para o mercado de trabalho, o trabalho procura mostrar como esse contexto afetou positivamente as formas de inserção dos jovens no mercado de trabalho brasileiro, tendências que foram colocadas em risco com o recente processo de estagnação/recessão da economia brasileira.

PALAVRAS-CHAVE: Mercado de trabalho, Jovens, Emprego, Desemprego, Políticas públicas.

ABSTRACT - The objective of this paper is to analyze the patterns of insertion of young people in the Brazilian labor market between 2004 and 2015. The analysis begins by characterizing the historical patterns of insertion of young people in the labor market in Brazil and the decades of relative economic stagnation between 1981 and 2003. Then, taking into account the ensuing demographic changes, the increased rate of economic growth and the social policies impacting the labor market, the paper seeks to show how this context positively affected the integration of young people into the Brazilian labor market - trends that have been jeopardized by the recent process of stagnation/recession of the Brazilian economy.

KEYWORDS: Labor market, Young people, Employment, Unemployment, Public policies.

Anselmo Luis dos Santos é doutor em Economia, professor do Instituto de Economia da Unicamp e diretor executivo do Cesit/IE/Unicamp. @ - anselmocesit@gmail.com

Denis Maracci Gimenez é doutor em Desenvolvimento Econômico, professor do Instituto de Economia da Unicamp e diretor Adjunto do Cesit/IE/Unicamp.

@ - maracci@ymail.com

I, II Instituto de Economia, Universidade Estadual de Campinas, Campinas/São Paulo, Brasil.

Recebido em 14.9.2015 e aceito em 28.9.2015. 